\title{
Diurnal Fibrous Meals for Healthy and Yielding Nocturnal Starch Assimilation: Nature Bioprocesses
}

\section{Akbar Nikkhah*}

Chief Highly Distinguished Professor, Department of Animal Sciences, University of Zanjan, Iran

This article develops an innovative pragmatic strategy to optimize starch assimilation in high-merit ruminant through optimizing sequence of fibrous and starch meals provision. The philosophy is based on natural circadian patterns of plant nutrient density and those of rumen and host ruminant metabolism capacity. Fibrous diurnal meals can allow high-producing ruminant effectively and healthfully bioprocess starch nocturnally. This is a lesson taught by nature for a sustainable global ruminant agriculture.

\section{Pragmatic Theory Development}

Basically, plants accumulate photosynthesis-driven highly digestible nutrients during day and utilize them via respiration overnight. Reports suggest that evening-cut forages are more nutritious and more digestible and induce more eating than morning-cut forage $[1,2]$. Such circadian patterns of natural plants have greatly contributed to corresponding circadian rhythms of rumen fermentation and ruminant splanchnoperipheral metabolism. Recent discoveries established that provision of the same total mixed ration to dairy cows at night vs. morning increased eating rate, rumen fermentation and milk energy production $[3,4]$. Therefore, the circadian nature of both feed nutrient content and ruminant physiology determine production response to management strategies.

Based on the above scientific well-established concepts, a theory is being constructed to help firmly develop a functional rumen fibre mat by feeding more fibrous ingredients during day to set the ruminal stage for healthy starch fermentation overnight. The theory gains support from the discovery that rumen realizes a larger volume and fermentation capacity overnight vs. morning and thus should be more tolerant of apparently unfavourable conditions e.g., overly high and fluctuated rumen acidity [5]. Starch has long challenged the modern ruminant industry in many ways [6-10]. Nature as an ultimate mentor of the global ruminant agriculture has led ruminants to evolve receiving more nutritious plants as day progressed into evening and night. As a result, the ruminant is more metabolically prepared to assimilate starch later in the evening and overnight. This natural pattern in ruminant production fuels the theory that provision of more fibrous meals during day for efficient and healthy utilization of more starchy meals delivered during evening and night can optimize animal production and health.

\section{Industrial Implication}

The modern ruminant agriculture must strive to be insightfully mentored by the Mother Nature. One significant lesson is to optimize starch use in high-merit ruminants through providing more fibrous diurnal meals for healthy bioprocessing of starchy meals delivered in evening and overnight.

\section{Acknowledgments}

Iran's Ministry of Science Research and Technology, National Elite Foundation, and University of Zanjan are thanked for supporting the author's global programs of optimizing science edification in the new millennium.

\section{References}

1. Fisher DS, Mayland HF, Burns JC (1999) Variation in ruminants' preference for tall fescue hays cut either at sundown or at sunup. J Anim Sci 77: 762-768.

2. Orr RJ, Penning PD, HaTvey A, Champion RA (1997) Diurnal patterns of intake rate by sheep grazing monocultures of ryegrass or white clover. Appl Animal Behav Sci 52: 65-77.

3. Nikkhah A (2013) Chronophysiology of ruminant feeding behavior and metabolism: an evolutionary review. Biol Rhythm Res 44: 197-218.

4. Nikkhah A (2012) Time of Feeding an Evolutionary Science. Lap Lamber Publishing, GmbH \& Co., KG, Germany.

5. Nikkhah A (2014) Review: Ruminant feed intake regulation evolution Chronophysiological rhythms perspectives. Biol Rhythm Res 45: 563-577.

6. Nikkhah A (2015) Gut Adaptation to Healthy Starch Assimilation in Dairy Ruminants: A Lifetime Development. J Adv Dairy Res 3: e117.

7. Nikkhah A (2012) Barley grain for ruminants: A global treasure or tragedy. J Anim Sci Biotechnol 3: 22.

8. Nikkhah A (2015) Production curve management of starch nutrition in ruminants: A global biotechnique. J Bioprocess Biotech 5:e123.

9. Nikkhah A (2015) Cereals bond trounces subacute rumen acidosis. Int J Vet Health Sci Res 3: 1-2.

10. Nikkhah A (2014) Steam bioprocessing philosophy of cereals for ruminants: time for a new history. J Bioprocess Biotech 4:e114.
*Corresponding author: Akbar Nikkhah, Chief Highly Distinguished Professor, Department of Animal Sciences, Faculty of Agricultural Sciences, University of Zanjan, Zanjan, Iran, National Elite Foundation, Tehran, Iran, Tel: +98-24-350328-01; Fax: +98-24-350-332-02; E-mail: nikkhah@znu.ac.ir

Received April 19, 2015; Accepted April 21, 2015; Published April 24, 2015

Citation: Nikkhah A (2015) Diurnal Fibrous Meals for Healthy and Yielding Nocturnal Starch Assimilation: Nature Bioprocesses. J Bioprocess Biotech 5: e130 doi:10.4172/2155-9821.1000e130

Copyright: (c) 2015 Nikkhah A. This is an open-access article distributed under the terms of the Creative Commons Attribution License, which permits unrestricted use, distribution, and reproduction in any medium, provided the original author and source are credited. 